Article

\title{
Remote Sensing of Agricultural Greenhouses and Plastic-Mulched Farmland: An Analysis of Worldwide Research
}

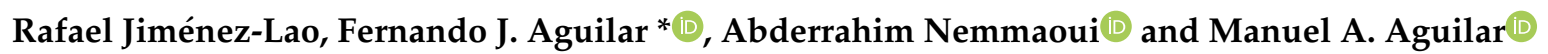 \\ Department of Engineering and Research Centre CIAIMBITAL, University of Almería, Carretera de Sacramento \\ s/n, La Cañada de San Urbano, 04120 Almería, Spain; rj1020@ual.es (R.J.-L.); an932@ual.es (A.N.); \\ maguilar@ual.es (M.A.A.) \\ * Correspondence: faguilar@ual.es; Tel.: +34-950-015-339; Fax: +34-950-015-491
}

Received: 15 July 2020; Accepted: 14 August 2020; Published: 17 August 2020

\begin{abstract}
The total area of plastic-covered crops of 3019 million hectares has been increasing steadily around the world, particularly in the form of crops maintained under plastic-covered greenhouses to control their environmental conditions and their growth, thereby increasing production. This work analyzes the worldwide research dynamics on remote sensing-based mapping of agricultural greenhouses and plastic-mulched crops throughout the 21st century. In this way, a bibliometric analysis was carried out on a total of 107 publications based on the Scopus database. Different aspects of these publications were studied, such as type of publication, characteristics, categories and journal/conference name, countries, authors, and keywords. The results showed that "articles" were the type of document mostly found, while the number of published documents has exponentially increased over the last four years, growing from only one document published in 2001 to 22 in 2019. The main Scopus categories relating to the topic analyzed were Earth and Planetary Sciences (53\%), Computer Science (30\%), and Agricultural and Biological Sciences (28\%). The most productive journal in this field was "Remote Sensing", with 22 documents published, while China, Italy, Spain, USA, and Turkey were the five countries with the most publications. Among the main research institutions belonging to these five most productive countries, there were eight institutions from China, four from Italy, one from Spain, two from Turkey, and one from the USA. In conclusion, the evolution of the number of publications on Remote Sensing of Agricultural Greenhouses and Plastic-Mulched Farmland found throughout the period 2000-2019 allows us to classify the subject studied as an emerging research topic that is attracting an increasing level of interest worldwide, although its relative significance is still very limited within the remote sensing discipline. However, the growing demand for information on the arrangement and spatio-temporal dynamics of this increasingly important model of intensive agriculture is likely to drive this line of research in the coming years.
\end{abstract}

Keywords: agricultural greenhouses; plastic-mulched farmland; remote sensing; mapping; bibliometric analysis; Scopus; SciVal

\section{Introduction}

The total area of agriculture plastic film, including plastic covered greenhouses (PCG), walk-in tunnels (high tunnels; HT), low tunnels (LT), and plastic-mulched farmland (PMF), has been steadily increasing throughout the world at a rate close to $20 \%$ per year [1], especially in China. This technology has been introduced and developed during the last 70 years as a tool to move up the first harvest and increase crops' yield, being considered a step forward in the evolution from extensive to intensive farming [2]. In this way, PCG have reached a total coverage of 3019 million hectares around the world, 
mainly located in China, Europe (Mediterranean areas), North Africa, and the Middle East [3]. China also has the largest area of plastic-mulched farmland in the world, with around 25 million hectares [4,5], and this area is growing rapidly [6].

Since its first use in 1948 [7], plastic covering has been widely used in the cultivation of vegetables and fruits to control environmental conditions and growth [8-10]. In the case of Mediterranean countries such as Spain, horticultural crops (tomato, pepper, zucchini, melon, watermelon, etc.) are the most frequent type of greenhouse crops, although plastic coverings are also often used for vines in Southern Italy. Likewise, plastic coverings are also beginning to be used for growing tropical fruits (woody crops) such as papaya, mango, loquat, nectarine, and citrus. Regarding low tunnels and plastic-mulched crops, the most frequent crops would be berries, asparagus, lettuce, and broccoli. In the case of China, flowers and vegetables (cabbage, tomato, beans, pepper, lettuce, and celery) form the basis of plastic-covered crops. It is also common to grow a very varied set of aromatic plants for culinary use and even crops such as cotton, rice, and wheat.

This technology can protect crops from adverse conditions, such as cold, heat, heavy rain, wind, harmful insects, and diseases, optimizing the use of water and increasing the soil temperature. However, plastic coverings also have negative impacts on the local or regional environment, since they reduce plant biodiversity by changing the pollination cycle and deteriorate the soil structure by leaving plastic film residues [11]. Furthermore, they produce large amounts of plastic and crop waste [12], also contributing to the contamination of aquifers and eutrophication of surface water due to fertilizer leaching [13]. Finally, land use and land cover (LULC) changes can directly affect the status and integrity of ecosystems. For instance, natural and multifunctional landscapes can be converted into areas of intensive farming, altering the main land use type and natural character of a region. In fact, the plastic covering-based agricultural model is linked to an important anthropic impact due to the construction of greenhouses and auxiliary infrastructures [12] that contribute significantly to the modification of the environment [14] and the increase in the visual impact [15]. In this sense, management decisions should promote a transition towards sustainable landscape strategies while simultaneously maintaining the delivery of ecosystem services [16].

The mentioned transition requires a deep understanding of the spatio-temporal distribution of plastic covered crops. Here, remote sensing seems to be the only feasible approach to obtain information on its impact on climate and environment in a large geographic area [17-19]. However, due to the peculiar characteristics of plastic coverings, such as different material and spectral signatures, types of crops and phenological status, age, state of conservation, and cleanliness of the plastic film, and local agricultural practice, remote sensing-based mapping of this particular type of land cover is still pending, judging by the increasing number of scientific works produced in the last few years [20].

Regarding the topic discussed in this work, several research lines have emerged throughout the 21st century based on (i) input satellite data sources; (ii) image processing approach (i.e., pixel-based (PB) or object-based image analysis (OBIA)); (iii) input vector features for image classification (multispectral or hyperspectral, geometrical, texture, 3D information, radar, lidar, and data fusion); (iv) image classification methods (unsupervised or supervised, parametric or non-parametric, and machine learning or deep learning-based approaches); (v) single or multitemporal remotely sensed data; vi) only mapping plastic covering structures or going a step further to classify and map plastic-covered crops. The following is a summary of a representative sample of papers dealing with the previously outlined research lines classified according to their primary focus on image processing (PB and OBIA), which is used to define the biunivocal relation between the pixels constituting an image and the classes of information set as the goal of the detection.

\subsection{Pixel-Based Approach}

The PB approach operates on single pixels and considers only their spectral and textural (moving window) characteristics. In this sense, Levin et al. [21] used the AISA-ES hyperspectral airborne sensor (1 $\mathrm{m}$ spatial resolution), together with the Landsat-5 Thematic Mapper (TM) and Landsat-7 
ETM + time series, to identify PCG. They reported that white and transparent plastic films presented three absorption peaks at $1218 \mathrm{~nm}, 1732 \mathrm{~nm}$, and $2313 \mathrm{~nm}$ wavelengths, which are not affected by dust, whitening, or the underlying surface. Agüera et al. [22] used the supervised parametric method maximum likelihood classifier (MLC) to identify PCG from a single QuickBird satellite image in order to later delineate the contour of classified greenhouses by applying an algorithm based on the Hough transformation. Agüera et al. [23] also applied MLC and texture analysis to compare Ikonos and QuickBird data in greenhouse mapping. Carvajal et al. [24] tested four increasing levels of atmospheric correction as a preprocessing step for PCG mapping over single Ikonos and QuickBird imagery, while Picuno et al. [25] combined supervised classification and geographic information system (GIS) analysis using Landsat TM images to assess the impact of agricultural plastic coverings on the landscape of Southern Italy. Koc-San [26] worked with WorldView-2 (WV2) satellite imagery to compare performance in mapping plastic and glass greenhouses in Turkey according to different classifiers such as MLC, random forest (RF), and support vector machine (SVM), achieving the best results with the SVM method. An unsupervised method to classify greenhouses based on an approximate spectral clustering ensemble using a hybrid geodesic similarity criterion was also tested by working on the same dataset [27], outperforming earlier unsupervised extraction methods. Lu et al. [11] developed a simple but robust decision tree (DT) classifier to detect PMF from only two Landsat-5 TM images taken during an agricultural season, proposing a specific index called the Plastic-Mulched Landcover Index (PMLI) based on red and shortwave infrared (SWIR)1 reflectance. With the same objective, Lu et al. [28] used dense time series of MODIS images (surface reflectance $250 \mathrm{~m}$ pixel size). Landsat-8 Operational Land Imager (OLI) imagery and GoogleEarth data (training phase) have been also used to map PMF using spectral and textural characteristics [29,30], while Hasituya et al. [31] also used full polarization SAR data (Radarsat-2) to classify PMF, obtaining poor overall accuracy of $75 \%$. In the same way, Novelli and Tarantino [32] combined Landsat-8 OLI and thermal infrared sensor (TIRS) data to provide several useful indices for mapping plastic-covered vineyards in Italy, while Yang et al. [33] developed a specific index for the detection of PCG (Plastic Greenhouse Index; PGI) from Landsat TM and Landsat-8 OLI images.

\subsection{Object-Based Image Analysis Approach}

Unlike the PB approach, the OBIA paradigm focuses on objects made of several pixels (segmentation step) that correspond to homogeneous and meaningful objects on the study site which are grouped according to both spectral and spatial information (e.g., 3D information). Furthermore, object analysis represents the ideal framework to carry out data fusion at the object level, obtaining a valuable features vector (including object texture, shape, and neighborhood) for further classification [34].

The OBIA approach to detect PCG and PMF is much more recent than PB analysis. Tarantino and Figorito [35] published the first work based on OBIA to map plastic-covered vineyards from true color aerial data in Southern Italy. Novelli et al. [20] carried out the first work based on Sentinel-2A Multispectral Instrument (MSI) and Landsat-8 OLI images to map PCG by adopting an OBIA approach and RF classifier. In this case, the segmentation step was performed on a very high resolution (VHR) image (WV2), thus focusing the classification step on the spectral information provided by Landsat-8 and Sentinel-2A data. Balcik et al. [36] employed Sentinel-2 images to classify greenhouses in Turkey, demonstrating the valuable contribution of the PGI index proposed in [33]. It is necessary to highlight that the OBIA approach has usually performed better than the PB approach, even working on medium resolution satellite imagery such as Landsat-8 OLI (e.g., [3]).

\subsection{Extraction of Greenhouses and Plastic-Mulched Farmland from Remote Sensing: Summary of Methods and Accuracy Results}

Regarding the PB approach, Agüera et al. [22] reported a PCG detection percentage value of 91.45\% when working on a single QuickBird image, but it was achieved after applying two algorithms to refine the raw classification. The same authors [23] compared single QuickBird and IKONOS imagery 
in PCG detection, obtaining overall accuracy values of $89.61 \%$ and $88.26 \%$ for QuickBird and IKONOS, respectively. They also concluded that the addition of texture information in the classification process did not improve the classification accuracy. Working on WV2 pan-sharpened imagery, Koc-San [26] reported overall accuracy values ranging from $87.80 \%$ to $93.88 \%$ by using different PB classification techniques (MLC, RF, and SVM), while Arcidiacono and Porto [37] reported a greenhouse detection percentage of $85.71 \%$ by using RGB very high resolution satellite bands only, although this accuracy was improved to $88.42 \%$ by adding texture descriptors. Lanorte et al. [38] used Landsat-8 OLI images and SVM classifier to identify PCG, reporting outstanding overall accuracy of $94.54 \%$. They subsequently utilized the classification data to spatially quantify the amount of agricultural plastic waste in Southern Italy.

With respect to the accuracy results provided by the OBIA approach, Arcidiacono and Porto [39] compared both PB and OBIA approaches to classify greenhouses from RGB aerial images over the same study site. They found that the best accuracy results, ranging from $83.15 \%$ to $94.73 \%$, were attained by using OBIA techniques. In the same way, Aguilar et al. [40] also applied OBIA on WV2 and GeoEye-1 imagery using nearest neighbor (NN) and SVM classifiers to achieve overall accuracy close to $90 \%$, while Tarantino and Figorito [35] achieved overall accuracy of $90.25 \%$ by using OBIA classification for mapping plastic-covered vineyards from high resolution aerial photographs.

These PB and OBIA classification results can be notably improved when using data fusion or time series. In fact, time series satellite images have proven to be a very interesting way to ensure the stability of the PCG/PMF classification results and their transferability to other areas [11,18]. For example, Lu et al. [11] used Landsat-5 TM images (two per agricultural season) and a DT classifier trained by analyzing the spectral characteristics of transparent PMF. The classifier was applied at the study area for years 1998, 2007, and 2011, achieving overall accuracy values of 95\%, 85.27\%, and 97.82\%, respectively. In the same research line, Hasituya and Chen [6] tried out RF and SVM classifiers on Landsat-8 OLI time series (up to five images per agricultural season) for mapping PMF through combining spectral bands, vegetation indices, texture, and thermal features, and the best overall accuracy value obtained was $97.01 \%$. González-Yebra et al. [2] applied OBIA data fusion combining panchromatic and RGB aerial images (pixel size ranging from $0.5 \mathrm{~m}$ to $1 \mathrm{~m}$ ) and Landsat-5 TM and Landsat-7 ETM + data for multitemporal mapping of PCG in Southern Spain, obtaining overall accuracy figures ranging from $92.05 \%$ to $98.58 \%$, while Novelli et al. [20] used OBIA classification (RF) on time series of Sentinel-2A MSI and Landsat-8 OLI images to provide overall accuracy values of up to $93.4 \%$. The same results were obtained by Aguilar et al. [41] through the combined use of very high resolution satellite data (WV2) and Landsat-8 OLI time series within the context of an OBIA and decision tree classification. In this case, WV2 was mainly used to segment the study area, focusing on individual greenhouses. In addition, Lu et al. [42] recently fused Sentinel-1 (SAR) and Sentinel-2 MSI (optical) data to classify PMF growing areas, achieving overall accuracy of $94.3 \%$ by applying the SVM classifier.

\subsection{Research Objective}

The current work aims to provide an overview of the general research dynamics regarding the topic of remote sensing-based mapping of agricultural greenhouses and plastic-mulched crops (RSAGPM henceforth) throughout the 21st century. In doing this, a quantitative analysis was carried out using bibliometric methods [43] to identify, organize, and analyze the main characteristics of scientific production within the mentioned research topic [44-46]. This information can be very valuable for researchers but also for analysts and decision-makers who may be interested in knowing how, where, and by whom research is being conducted on the arrangement and spatio-temporal dynamics of this increasingly important model of intensive agriculture to guarantee its sustainability and capacity to produce quality food at a relatively affordable cost. 


\section{Materials and Methods}

\subsection{Bibliometric Method}

A traditional bibliometric analysis of scientific documents based on co-occurrence analysis applied to database metadata (e.g., the year of publication, authors' names, institutions and countries, topic categories, article citations, and keywords [47]) was undertaken according to indicators classified into three main groups: productivity, quality, and structure [48].

Regarding productivity indicators, the bibliometric analysis has been focused on the number of indexed articles and conference papers related to remote sensing-based mapping of agricultural greenhouses and plastic-mulched farmland, as well as the authors, journals, institutions, and countries involved in these documents.

The scientific quality indicators analyzed in the present work are addressed by some of the best known and used parameters, such as the number of citations, the author/journal h-index [49], and the Scimago Journal Rank (SJR) impact factor of journals [45]. Both h-index and SJR are impact indices designed to improve simpler measures such as the total number of citations or publications. For example, the journal/author $h$-index is defined as the maximum value of $h$, such that the given journal/author has published $h$ papers that have each been cited at least $h$ times [49]. In this way, it accounts for quantity (number of articles) and quality (defined as number of citations). In the case of measuring journal impact (journal ranking), SJR is calculated as the ratio of the average number of weighted citations received in a year over the number of documents published in the journal in the previous three years, thus accounting for the number of citations received by a journal and the importance and prestige of the journal where the citations come from [50].

Finally, the structure indicators were headed up to find linking networks between active agents and identified research trends in the field of RSAGPM through applying mapping tools such as VOSviewer [51,52].

\subsection{Data Processing}

Most bibliometric analyses are based on Thomson Reuters' Web of Science (WoS) and Elsevier's Scopus. In this work, the Scopus database was chosen as it is considered the largest repository of data on citations and summaries of peer-reviewed literature, also providing great availability [45]. Furthermore, Scopus includes more indexed journals than WoS [53]; it is remarkable that, while $84 \%$ of the WoS indexed titles can be found in Scopus, only $54 \%$ of the Scopus indexed publications are found in WoS [54].

The following keywords were typed into Scopus to find indexed publications relevant to this bibliometric analysis: "(TITLE-ABS-KEY (greenhouse OR plasticulture OR mulch OR mulched OR plastic OR "plastic-mulched" OR crop-shelter OR "mar de" OR cropshelter) AND TITLE-ABS-KEY (image OR imagery OR satellite OR uas OR uav OR rpas OR dron OR lidar OR sar OR radar OR "aerial orthoimages" OR hyperspectral OR multispectral OR "aerial orthophoto" OR landsat OR sentinel OR "aerial data")". The search was conducted in May 2020, while the target study period was 2000 to 2019, trying to cover all indexed Scopus items (document type: article, review, letter, and conference paper) related to the studied topic published throughout the 21st century. Note that only documents dated until 2019 were included to compare full 12-month periods [46]. Furthermore, some preprocessing tasks were performed in order to correct common mistakes, such as duplications, misspellings, and variant names [44]. It is important to note that modifying the search parameters varies the results. Although the initial number of elements found was high, it was reduced to 107 RSAGPM documents after ruling out most of them by performing a manual review based on keywords, author analysis, and abstract reading.

The analyzed variables were the number of publications per year, type of document, author, institution, country, subject area, journal, and keyword. After downloading this information in RIS and CSV formats, careful manual processing was performed to remove duplicates and unrelated items, 
obtaining a final database from which different tables and figures were drawn up in order to facilitate the analysis of the information collected. Both Excel (version 2016, Microsoft, Redmond, WA, USA) and SciVal (Elsevier) were used to undertake these tasks. VOSviewer (version 1.6.15, Leiden University, Leiden, the Netherlands) was also used to build the corresponding network maps due to its wide use in this kind of study [55] (Figure 1). An additional study of the relevant keywords within the RSAGPM topic was conducted by applying the tool VOSviewer to create a map of a co-occurrence network of keywords and identify current research trends.

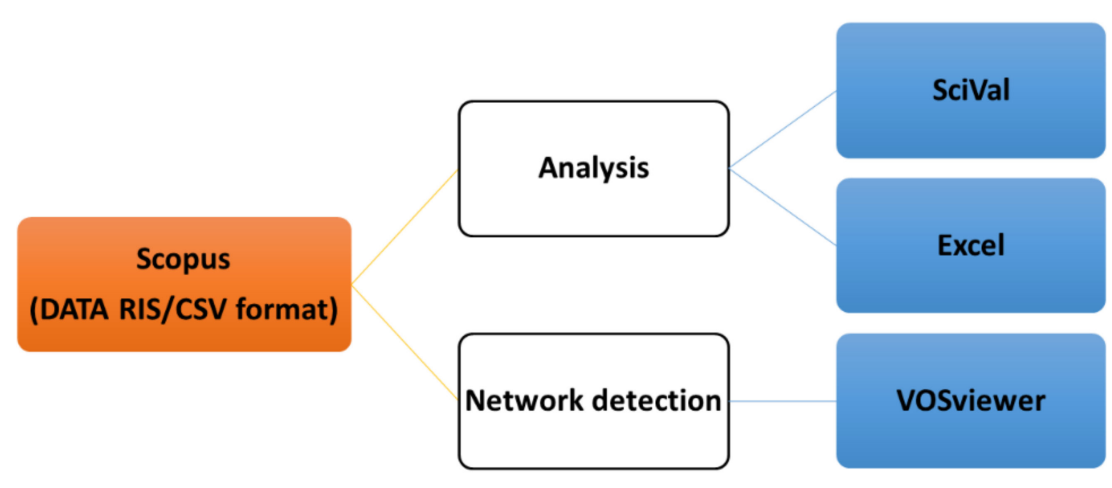

Figure 1. Simplified flowchart for data screening and analysis.

\section{Results}

\subsection{Types and Languages of Publications}

The chosen time frame, which includes the last 20 years, returned 107 documents, including 71 articles $(66 \%), 34$ conference papers (32\%), and, to a lesser extent, one review (1\%) and one letter $(1 \%)$.

Considering the international scope of the indexed documents, English was the most common language, comprising 101 (95\%) out of the 107 documents in the database. The remaining languages presented limited use, with four documents in Chinese (4\%), one in Korean (1\%), and one in Spanish $(1 \%)$.

\subsection{Scientific Production and Characteristics}

The analysis of the number of documents published during 2000-2019 shows that research on RSAGPM has attracted increasing attention in recent years (Table 1). In fact, most documents (55.2\%) were published in the last four years (2016-2019), while the greatest number of documents were published in 2019 (20.6\%). This proves that RSAGPM is an emerging topic in continuous progress that will probably increase its number of publications in the next few years.

Figure 2 depicts how the number of documents published within this thematic field has grown exponentially during the period 2000-2019. This growing interest in this topic is also shown by the increase in the number of authors, journals, and countries. In this sense, the number of authors (AU) increased from just one in 2001 to 94 in 2019. The number of publications in journals (J) (excluding conference papers) also increased from one in 2003 to 18 in 2019, while the number of countries (C) to which their authors belonged rose from one to 23 between 2001 and 2019. In summary, and excluding year-on-year repetitions, 160 authors, 46 Scopus indexed journals and conferences, and 23 countries were involved in the publication of the 107 documents included in the sample, showing the growth of this topic, which is becoming a notable field of research for the remote sensing scientific community. This increasing impact can also be deduced from the up to 1014 references (number of references; NR) cited in the 22 articles published in 2019 and the 1453 total citations (TC) referring to the 107 sample documents accumulated from 2000 to 2019 (Table 1). 
Table 1. Relevant characteristics of the documents related to the topic RSAGPM from 2000 to 2019.

\begin{tabular}{|c|c|c|c|c|c|c|c|c|c|}
\hline Year & $\mathbf{A}$ & NR & NR/A & TC & TC/CA & AU & AU/A & $\mathbf{J}$ & C \\
\hline 2000 & 0 & - & - & - & - & - & - & - & - \\
\hline 2001 & 1 & 27 & 27.0 & 12 & 12.0 & 1 & 1.0 & 0 & 1 \\
\hline 2002 & 2 & 12 & 6.0 & 5 & 2.5 & 6 & 3.0 & 0 & 2 \\
\hline 2003 & 2 & 33 & 16.5 & 168 & 84 & 4 & 2.0 & 1 & 2 \\
\hline 2004 & 2 & 28 & 14.0 & 14 & 7.0 & 11 & 5.5 & 1 & 3 \\
\hline 2005 & 1 & 9 & 9.0 & 0 & 0.0 & 4 & 4.0 & 0 & 1 \\
\hline 2006 & 3 & 59 & 19.7 & 46 & 15.3 & 10 & 3.3 & 2 & 3 \\
\hline 2007 & 2 & 50 & 25.0 & 61 & 30.5 & 9 & 4.5 & 2 & 2 \\
\hline 2008 & 7 & 117 & 16.7 & 198 & 28.3 & 17 & 2.4 & 2 & 4 \\
\hline 2009 & 1 & 22 & 22.0 & 38 & 38.0 & 2 & 2.0 & 1 & 2 \\
\hline 2010 & 1 & 46 & 46.0 & 26 & 26.0 & 2 & 2.0 & 1 & 1 \\
\hline 2011 & 4 & 144 & 36.0 & 78 & 19.5 & 15 & 3.8 & 3 & 4 \\
\hline 2012 & 5 & 86 & 17.2 & 74 & 14.8 & 8 & 1.6 & 5 & 2 \\
\hline 2013 & 3 & 136 & 45.3 & 79 & 26.3 & 9 & 3.0 & 2 & 4 \\
\hline 2014 & 6 & 187 & 31.2 & 99 & 16.5 & 10 & 1.7 & 5 & 6 \\
\hline 2015 & 8 & 248 & 31.0 & 94 & 11.8 & 24 & 3.0 & 4 & 5 \\
\hline 2016 & 15 & 622 & 41.5 & 248 & 16.5 & 49 & 3.3 & 9 & 6 \\
\hline 2017 & 11 & 514 & 46.7 & 133 & 12.1 & 38 & 3.5 & 8 & 5 \\
\hline 2018 & 11 & 439 & 39.9 & 48 & 4.4 & 37 & 3.4 & 7 & 7 \\
\hline 2019 & 22 & 1014 & 46.1 & 32 & 1.5 & 94 & 4.3 & 18 & 10 \\
\hline 00-2019 & 107 & 3793 & 35.4 * & 1453 & $13.6^{*}$ & $160 * *$ & $3.3^{*}$ & 71 & $23^{* *}$ \\
\hline
\end{tabular}

A: The annual number of total documents; NR: the number of references in total publications; NR/A: the annual number of references per publication; TC: the annual number of citations in cumulative publications; TC/CA: annual total citations per cumulative publication, AU: the annual number of authors; J: the annual number of publications in journals; C: the annual number of countries. $\left(^{*}\right)$ : Average value per publication; $\left({ }^{* *}\right)$ : Excluding year-on-year repetitions.

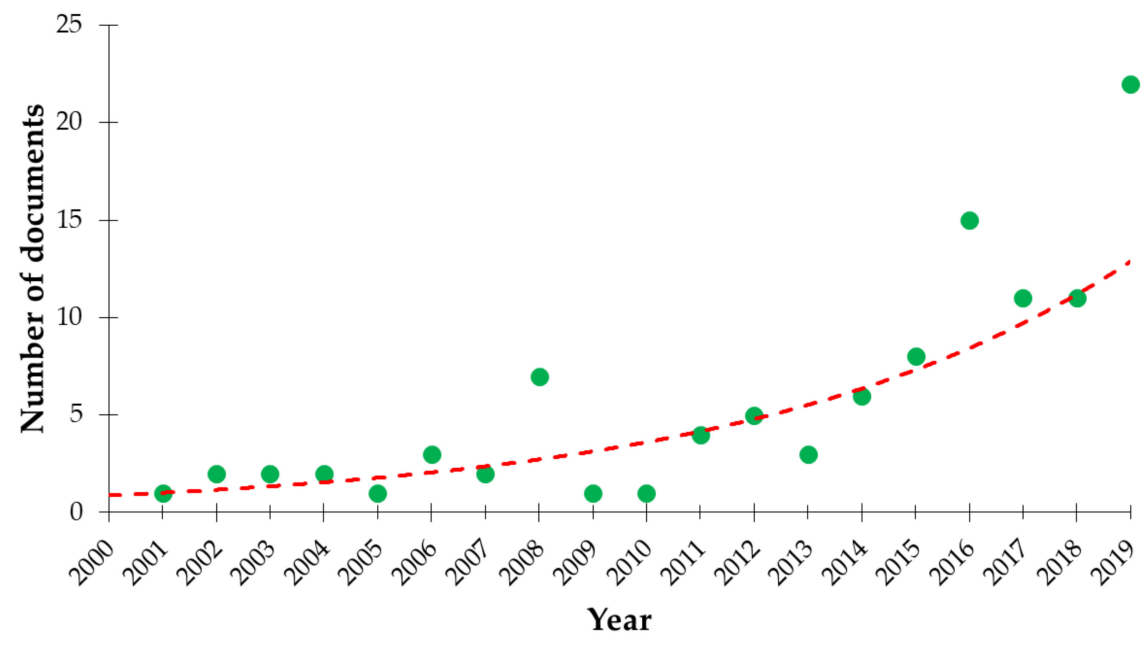

Figure 2. Trend in number of RSAGPM published documents.

\subsection{Subject Categories and Journals/Conferences}

The documents published on RSAGPM between 2000 and 2019 were classified into 15 different categories according to the Scopus database, which can be considered a clear indication of the wide interest that this field of research has aroused in the scientific community. Figure 3 shows the evolution of the principal subject categories into which Scopus classified the 107 documents related to RSAGPM. It is worth noting that each document may be allocated to two or more categories at the same time. In this way, a significant portion of the sample was attributed to three domains, classifying up to $53 \%$ of the published documents as Earth and Planetary Sciences, 30\% as Computer Science, and 28\% as Agricultural and Biological Sciences. The classification was changing between the main categories just 
at the beginning of the period considered due to the low number of registered publications. However, a more consistent trend is observed at the end of the period, where the three predominant categories stand out along with the emergence of the category of Environmental Science.

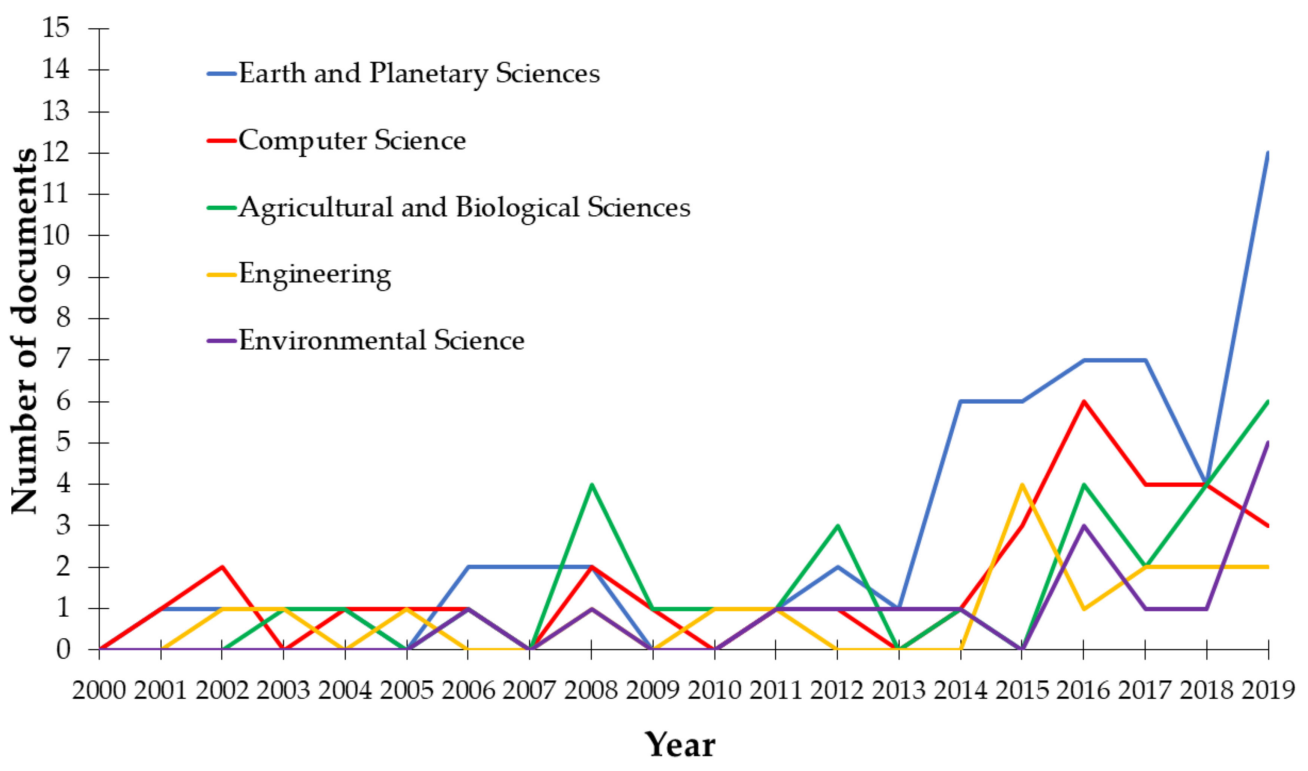

Figure 3. Evolution of the distribution of publications on RSAGPM by Scopus category.

The 15 Scopus indexed journals and conferences with the highest number of published works on RSAGPM from 2000 to 2019 are presented in Table 2. To facilitate the analysis during the period analyzed, five sub-periods of three years were distinguished. The most productive journal in this field was "Remote Sensing", which was launched in 2009, and it is currently leading the list of the top journals, with 22 documents. The first article in this journal related to RSAGPM (first A in Table 2) appeared in 2012. However, it did not take the first place in the number of articles published until the last sub-period analyzed. It is also the journal with the most citations. The second journal with the largest number of published articles is "Acta Horticulturae", which achieved the first position in two sub-periods (2000 to 2003 and 2008 to 2011).

With respect to journal impact indicators, "Remote Sensing" is the journal that accumulated the highest total number of citations on RSAGPM (254), followed by "Institute of Electrical and Electronics Engineers (IEEE) Transactions on Geoscience and Remote Sensing" (186) and "International Society of Photogrammetry and Remote Sensing (ISPRS) Journal of Photogrammetry and Remote Sensing" (145) (Table 2). This result is clearly associated with the general impact of each journal, with "IEEE Transactions on Geoscience and Remote Sensing" and "ISPRS Journal of Photogrammetry and Remote Sensing" being the journals with the highest numbers of citations per article, with 93 and 72.5 citations per article published on RSAGPM, respectively. This means that these two journals, together with "Landscape and Urban Planning" (44 citations per article), have a great impact on the RSAGPM topic. Note that the number of citations per article is closely related to the age of publication, it being more likely that an article accumulates more citations as more time passes after its publication.

Regarding quality indices (Table 2), "ISPRS Journal of Photogrammetry and Remote Sensing" was the journal that published articles on RSAGPM with the highest SJR index (3.122), followed by "IEEE Transactions on Geoscience and Remote Sensing" (2.616). Furthermore, most of the documents on RSAGPM were found to be situated within the first quartile according to their SJR (2019 SJR edition) index, which demonstrates the high quality of international journals covering this emerging topic. It is necessary to recall that an SJR index of 1.0 means that a journal's articles are cited at the average rate for all journals in the same subject area, while an SJR index over 1.0 indicates more citations than average in the field and vice versa. An SJR index of more than 1.5 generally indicates a very well-cited journal. 
Table 2. Characteristics of the top 15 most productive Scopus indexed journals and conferences on RSAGPM from 2000 to 2019

\begin{tabular}{|c|c|c|c|c|c|c|c|c|c|c|c|c|}
\hline & & & & & & & & & & $\mathbf{R}(\mathrm{A})$ & & \\
\hline Journal/Conference & A & SJR & C & TC & TC/A & h & 1st A & 2000-2003 & 2004-2007 & 2008-2011 & 2012-2015 & 2016-2019 \\
\hline Remote Sensing & 22 & $1.422(\mathrm{Q} 1)$ & Switzerland & 254 & 11.5 & 99 & 2012 & 0 & 0 & 0 & $2(3)$ & $1(19)$ \\
\hline Acta Horticulturae & 8 & $0.184(\mathrm{Q} 4)$ & Belgium & 57 & 7.1 & 54 & 2003 & $1(1)$ & 0 & $1(4)$ & $3(2)$ & $8(1)$ \\
\hline $\begin{array}{c}\text { International Geoscience and Remote Sensing } \\
\text { Symposium (IGARSS) }\end{array}$ & 7 & 0.279 & Spain & 19 & 2.7 & 62 & 2002 & $4(1)$ & $2(2)$ & $6(1)$ & $4(2)$ & $17(1)$ \\
\hline Computers and Electronics in Agriculture & 4 & $1.058(\mathrm{Q} 1)$ & Netherlands & 89 & 22.3 & 104 & 2009 & 0 & 0 & $4(1)$ & 0 & $3(3)$ \\
\hline International Journal of Remote Sensing & 4 & $0.928(\mathrm{Q} 1)$ & United Kingdom & 118 & 29.5 & 164 & 2006 & 0 & $1(3)$ & $7(1)$ & 0 & 0 \\
\hline Journal of Applied Remote Sensing & 4 & $0.494(\mathrm{Q} 2)$ & United States & 61 & 15.3 & 43 & 2013 & 0 & 0 & 0 & $1(3)$ & $21(1)$ \\
\hline $\begin{array}{l}\text { Proceedings of SPIE - The International Society for } \\
\text { Optical Engineering }\end{array}$ & 4 & 0.215 & United States & 7 & 1.8 & 162 & 2002 & $5(1)$ & $4(1)$ & $9(1)$ & $13(1)$ & 0 \\
\hline Smart Innovation, Systems and Technologies & 3 & $0.180(\mathrm{Q} 3)$ & Germany & 9 & 3.0 & 18 & 2018 & 0 & 0 & 0 & 0 & $4(3)$ \\
\hline $\begin{array}{l}\text { IEEE Journal of Selected Topics in Applied Earth } \\
\text { Observations and Remote Sensing }\end{array}$ & 2 & $1.480(\mathrm{Q} 1)$ & United States & 47 & 23.5 & 73 & 2014 & 0 & 0 & 0 & $9(1)$ & $15(1)$ \\
\hline Biosystems Engineering & 2 & $0.857(\mathrm{Q} 1)$ & United States & 29 & 14.5 & 100 & 2010 & 0 & 0 & $3(1)$ & 0 & $10(1)$ \\
\hline Agricultural Water Management & 2 & $1.369(\mathrm{Q} 1)$ & Netherlands & 19 & 9.5 & 119 & 2014 & 0 & 0 & 0 & $8(1)$ & $9(1)$ \\
\hline ISPRS Journal of Photogrammetry and Remote Sensing & 2 & $3.122(\mathrm{Q} 1)$ & Netherlands & 145 & 72.5 & 126 & 2008 & 0 & 0 & $5(1)$ & 0 & $16(1)$ \\
\hline Remote Sensing Letters & 2 & $0.822(\mathrm{Q} 1)$ & United Kingdom & 23 & 11.5 & 35 & 2015 & 0 & 0 & 0 & $14(1)$ & $28(1)$ \\
\hline IEEE Transactions on Geoscience and Remote Sensing & 2 & $2.616(\mathrm{Q} 1)$ & United States & 186 & 93.0 & 236 & 2015 & $3(1)$ & 0 & 0 & $10(1)$ & 0 \\
\hline Landscape and Urban Planning & 2 & $1.740(\mathrm{Q} 1)$ & Netherlands & 88 & 44.0 & 149 & 2008 & 0 & 0 & $2(2)$ & 0 & 0 \\
\hline
\end{tabular}

A: number of total publications; SJR: Scopus Journal Ranking (year 2019); C: country; TC: number of citations in total publications; TC/A: total citations per publication; h: journal h-index (year 2019); 1st A: first publication in RSAGPM research by journal; R: ranking position. 
With respect to the h-index (2019 SJR edition), "IEEE Transactions on Geoscience and Remote Sensing" presents the highest value (236), followed by "International Journal of Remote Sensing" (164) and "Proceedings of SPIE - The International Society for Optical Engineering" (162). In this case, prestigious journals such as "Landscape and Urban Planning" (149) and "ISPRS Journal of Photogrammetry and Remote Sensing" (126) are one step below. Note that journals that started recently have not accumulated enough citations to increase their h-index yet (this may be the case for the journal "Remote Sensing"), as an article will not generate a number of citations until some years after publication. In this sense, Hirsch [49] estimates that, after 20 years of research, an h-index of 20 is good, 40 is outstanding, and 60 is truly exceptional.

It should be noted that just five journals are from the USA, publishing altogether around $13 \%$ of the total documents on RSAGPM. The remaining journals are from Europe (four of them from the Netherlands), and together they have published around 53\% of RSAGPM documents.

\subsection{Countries, Institutions, and Authors}

The topic analyzed in this work has been investigated by researchers belonging to up to 23 countries, proving again the great interest that RSAGPM has attracted worldwide (Table 3). In this analysis, each of the authors who appear in the documents has been considered. In this way, the same document can be assigned to more than one country if the authors are of different nationalities (i.e., international collaboration). China ranked first, followed by Italy and Spain, which published more than 20 publications each in the period analyzed. It should be noted that $75 \%$ of the publications in China were published in the last sub-period analyzed. Table 3 also shows the number of documents published per million inhabitants of each country (APC). If this variable is considered, Spain ranks first, practically tied with Italy, also having the largest number of total citations, followed by Italy and China. However, considering the number of citations per publication, the Netherlands took first place, with 89.5 citations per publication, followed by Spain (20.58) and Italy (16.2).

Table 3. The top 9 most productive countries in RSAGPM research from 2000 to 2019.

\begin{tabular}{|c|c|c|c|c|c|c|c|c|c|}
\hline \multirow[b]{2}{*}{ Country } & \multirow[b]{2}{*}{$\mathbf{A}$} & \multirow[b]{2}{*}{ APC } & \multirow[b]{2}{*}{ TC } & \multirow[b]{2}{*}{ TC/A } & \multicolumn{5}{|c|}{$\mathbf{R}(\mathbf{A})$} \\
\hline & & & & & 2000-2003 & 2004-2007 & 2008-2011 & 2012-2015 & 2016-2019 \\
\hline China & 37 & 0.03 & 302 & 8.16 & 0 & $1(4)$ & $4(1)$ & $3(4)$ & $1(28)$ \\
\hline Italy & 30 & 0.50 & 486 & 16.20 & $2(1)$ & 0 & $1(7)$ & $1(9)$ & $2(13)$ \\
\hline Spain & 24 & 0.51 & 494 & 20.58 & $4(1)$ & $4(1)$ & $2(3)$ & $2(6)$ & $3(13)$ \\
\hline United States & 15 & 0.05 & 177 & 11.80 & 0 & $6(1)$ & 0 & $4(4)$ & $4(10)$ \\
\hline Turkey & 11 & 0.13 & 69 & 6.27 & 0 & $5(1)$ & 0 & $5(3)$ & $5(7)$ \\
\hline Japan & 5 & 0.04 & 35 & 7.00 & $3(1)$ & $3(1)$ & $5(1)$ & $9(1)$ & $13(1)$ \\
\hline Germany & 3 & 0.04 & 3 & 1.00 & 0 & 0 & 0 & $7(1)$ & $6(2)$ \\
\hline Netherlands & 2 & 0.12 & 179 & 89.50 & $1(2)$ & 0 & 0 & 0 & 0 \\
\hline South Korea & 2 & 0.04 & 3 & 1.50 & 0 & 0 & $6(1)$ & $10(1)$ & 0 \\
\hline
\end{tabular}

A: number of total publications; APC: number of documents per 1M inhabitants; TC: number of citations in total publications; TC/A: total citations per publication; R: ranking position.

Figure 4 shows a network illustrating the international collaboration between publishing countries on RSAGPM. The size of each circle has been scaled with the number of publications of each country, while the thickness of each line joining two countries represents the number of collaborations between them. The assigned color allows us to distinguish the different groups formed by sets of countries (network cluster). As can be seen in Figure 4, three main clusters can be differentiated. The first cluster (red) is led by China, the most productive country. The second cluster (green) is headed by Italy, while the third (blue) is led by Spain, which presents a strong collaboration with Italy. 


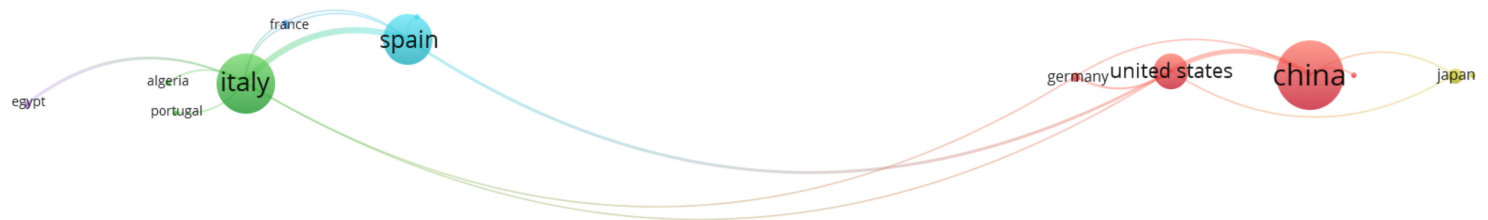

Figure 4. Network of the co-authorship-based collaboration between countries.

Table 4 presents data regarding the international collaborations of the most productive countries regarding the RSAGPM topic. The parameters shown refer to the percentage of publications that each country produced in collaboration with another (IC), the number of countries with which such collaborations occurred (NC), and the main collaborating countries. In this regard, Germany only published documents produced in collaboration with other countries. The United States produced up to $80 \%$ of their documents in collaboration with other countries, although Italy was determined to be the country with the largest number of collaborations (nine countries). On the contrary, both Turkey and the Netherlands did not show collaborations with other countries in the RSAGPM research area between 2000 and 2019.

Table 4. International collaboration between countries in RSAGPM research from 2000 to 2019.

\begin{tabular}{cccccc}
\hline Country & \multirow{2}{*}{ IC $\%$} & \multirow{2}{*}{ NC } & Main Collaborators & \multicolumn{2}{c}{ TC/A } \\
\cline { 4 - 6 } & & 4 & The United States, Japan, Germany, Australia & 14.11 & NIC \\
\hline China & 24.32 & & Spain, Portugal, United states, Germany, Egypt, & 16.20 & 16.20 \\
Italy & 50.00 & 9 & Algeria, France, Greece, Saudi Arabia & 19.73 & 22.00 \\
Spain & 62.50 & 5 & Italy, France, Greece, United States, United Kingdom & 12.08 & 8.00 \\
United States & 80.00 & 4 & Germany, Spain, Japan, China & 0.00 & 6.27 \\
Turkey & 0.00 & 0 & - & 2.00 & 10.33 \\
Japan & 40.00 & 3 & United States, China, South Korea & 3.67 & 0.00 \\
Germany & 100.00 & 3 & United states, China, Italy & 0.00 & 89.50 \\
Netherlands & 0.00 & 0 & - & 3.00 & 0.00 \\
South Korea & 50.00 & 1 & Japan
\end{tabular}

IC: international collaborations; NC: total number of international collaborators; TC/A: total citation per publication; NIC: no international collaborations.

The main production and impact indicators of the institutions with the highest number of publications on RSAGPM are depicted in Table 5. Note that some publications were authored by researchers belonging to different countries and institutions. Therefore, the total number of publications by country/institution in Table 5 is greater than the number of publications in the sample (107). The University of Almeria is in first place, with a total of 23 documents published between 2000 and 2019. It is followed by Zhejiang University, with 11 documents, while the Chinese Academy of Sciences, the Polytechnic of Bari, and the Chinese Academy of Agricultural Sciences contributed 10 publications each. With respect to the total number of citations, the University of Almeria had 452 citations, followed by Zhejiang University with 192, the Polytechnic of Bari with 189, and the University of Basilicata with 116.

When considering the average number of citations per publication, the Nederlandse Organisatie voor toegepast natuurwetenschappelijk onderzoek (TNO) (Netherlands) ranked first, with 89.5 citations per document, although it does not appear in Table 5 because it only published two articles in the period analyzed. George Mason University took the second position, with 20.5 citations per publication, while the University of Maryland, also absent in Table 5 as it had only two publications, had the third position, with 20 citations per document. Both universities were closely followed by the University of Almeria and the University of Basilicata, which scored 19.65 and 19.33 citations per article, respectively. It was observed that there are some institutions that only had publications in international collaborations, as is the case of Ohio State University, not counting a research group specifically focused on RSAGPM. 
Table 5. Characteristics of the main institutions in RSAGPM research from 2000 to 2019.

\begin{tabular}{|c|c|c|c|c|c|c|}
\hline & Institution & $\mathrm{C}$ & A & TC & TC/A & $\mathrm{IC} \%$ \\
\hline 1 & Universidad de Almeria & Spain & 23 & 452 & 19.65 & $61 \%$ \\
\hline 2 & Zhejiang University & China & 11 & 192 & 17.45 & $73 \%$ \\
\hline 3 & Chinese Academy of Sciences & China & 10 & 32 & 3.20 & $20 \%$ \\
\hline 4 & Politecnico di Bari & Italy & 10 & 189 & 18.90 & $60 \%$ \\
\hline 5 & Chinese Academy of Agricultural Sciences & China & 10 & 90 & 9.00 & $20 \%$ \\
\hline 6 & Akdeniz Üniversitesi & Turkey & 8 & 68 & 8.50 & $0 \%$ \\
\hline 7 & Ministry of Agriculture of the People's Republic of China & China & 8 & 77 & 9.63 & $13 \%$ \\
\hline 8 & Università degli Studi della Basilicata & Italy & 6 & 116 & 19.33 & $50 \%$ \\
\hline 9 & Università degli Studi di Catania & Italy & 5 & 72 & 14.40 & $0 \%$ \\
\hline 10 & Università degli Studi di Bari & Italy & 5 & 93 & 18.60 & $40 \%$ \\
\hline 11 & Ministry of Education China & China & 4 & 1 & 0.25 & $25 \%$ \\
\hline 12 & George Mason University, Fairfax Campus & USA & 4 & 82 & 20.50 & $100 \%$ \\
\hline 13 & Beijing Normal University & China & 4 & 25 & 6.25 & $25 \%$ \\
\hline 14 & University of Chinese Academy of Sciences & China & 4 & 5 & 1.25 & $0 \%$ \\
\hline 15 & $\begin{array}{c}\text { Institute of Geographical Sciences and Natural Resources } \\
\text { Research Chinese Academy of Sciences }\end{array}$ & China & 4 & 23 & 5.75 & $0 \%$ \\
\hline 16 & Antalya Bilim University & Turkey & 3 & 12 & 4.00 & $0 \%$ \\
\hline
\end{tabular}

C: country; A: number of total publications per institution; TC: number of citations in total publications; TC/A: total citations per publication; IC: international collaborations (\%).

Figure 5 shows a network map illustrating collaborative co-authorship on RSAGPM from 2000 to 2019, where the different colors represent the clusters made up of different authors who usually collaborate with each other. From the obtained results, the most interrelated co-authorships are shown. Although several clusters are observed, mainly two can be pointed out. One is made up of mainly Chinese authors and the other is composed of Spanish and Italian authors. In this sense, it can be stated that these are the two more relevant research groups currently working on RSAGPM around the world. In addition, a highly complex and atomized collaboration network is observed within them.

schettini, e.

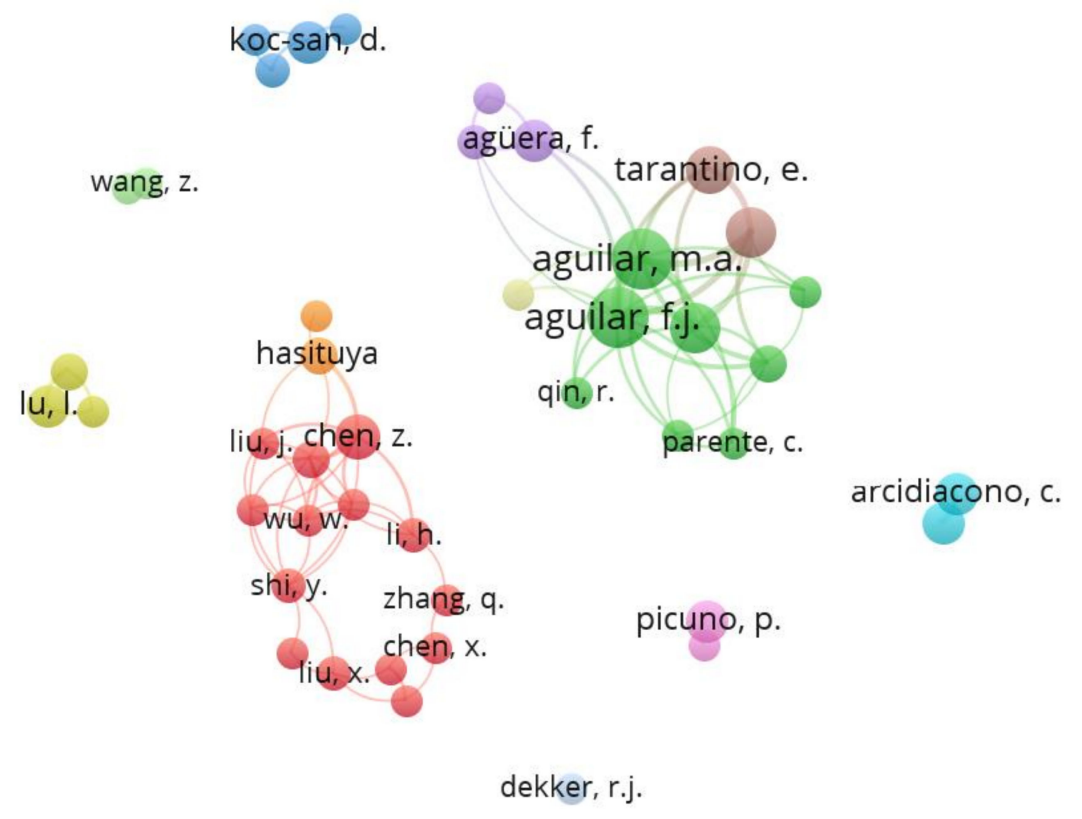

Figure 5. Collaboration network based on co-authorship between authors.

Table 6 includes the most productive authors within the topic analyzed in this work, showing the main variables related to production (A) and the impact of their publications (TC). In addition, it depicts some reference data related to the author's affiliation, country $(C)$, year of their first publication (First P), and last publication on RSAGPM (Last P). The first three authors of the list belong to the University of Almeria, with more than 10 publications each. All authors listed in Table 6 come from the 
five most productive countries (Table 3) and they represent up to 11 different institutions. The author with the most publications in the list is Aguilar, M.A. [22] from Spain. All authors listed in Table 6 published their last document on RSAGPM between 2016 and 2019, indicating that they continue to work on this topic. The only exception is the case of Porto, S.M.C., whose last article is dated 2012.

Table 6. The most productive authors in RSAGPM research from 2000 to 2019.

\begin{tabular}{ccccccccc}
\hline & Author & A & TC & h-Index & C & Affiliation & First P & Last P \\
\hline 1 & Aguilar, M.A. & 18 & 383 & 21 & Spain & Universidad de Almeria & 2006 \\
2 & Aguilar, F.J. & 17 & 382 & 21 & Spain & Universidad de Almeria & 2019 \\
3 & Nemmaoui, A. & 10 & 142 & 6 & Spain & Universidad de Almeria & 2006 \\
4 & Novelli, A. & 9 & 151 & 10 & Italy & EURAC Research & 2019 \\
5 & Tarantino, E. & 8 & 153 & 14 & Italy & Politecnico di Bari & 2015 \\
6 & Agüera, F. & 6 & 229 & 20 & Spain & Universidad de Almeria & 2019 \\
7 & Chen, Z. & 6 & 118 & 21 & China & Chinese Academy of Agricultural Sciences & 2018 \\
8 & Koc-San, D. & 6 & 57 & 9 & Turkey & Akdeniz Üniversitesi & 2016 \\
9 & Picuno, P. & 6 & 116 & 15 & Italy & Università degli Studi della Basilicata & 2013 \\
10 & Arcidiacono, C. & 5 & 72 & 14 & Italy & Università degli Studi di Catania & 2013 \\
11 & Lu, L. & 5 & 82 & 7 & China & School of Earth Sciences, Zhejiang University & 2019 \\
12 & Porto, S.M.C. & 5 & 72 & 15 & Italy & Università degli Studi di Catania & 2014 \\
13 & Di, L. & 4 & 82 & 28 & USA & George Mason University, Fairfax & 2018 \\
14 & Hasituya & 4 & 68 & 4 & China & Agricultural University Hohhot & 2019 \\
15 & García-Lorca, A.M. & 4 & 66 & 5 & Spain & Universidad de Almeria & 2014 \\
16 & Carvajal, F. & 3 & 34 & 15 & Spain & Universidad de Almeria & 2019 \\
17 & Tasdemir, K. & 3 & 12 & 14 & Turkey & Antalya Bilim University & 2015 \\
18 & Wang, L. & 3 & 103 & 14 & China & Chinese Academy of Agricultural Sciences & 2018 \\
\end{tabular}

A: number of total publications; TC: number of citations in total publications; h-index: Scopus h-index; C: country; (First P): year of first publication; (Last P): year of last publication.

\subsection{Keyword Analysis}

The 18 most frequently used keywords in publications on RSAGPM are displayed in Table 7 for the period analyzed in this work. The period was conveniently divided into five sub-periods to study the evolution of keywords. The data shown in Table 7 refer to the position that keywords occupied in each sub-period compared with the total number of keywords of the sample, the number of publications in which it appeared $(\mathrm{R}(\mathrm{A}))$, and the repetition percentage (\%). As expected, the terms most recurrent during the entire study period were "Remote Sensing" and "Greenhouse/Greenhouses". These keywords also took the first positions in the ranking by sub-period.

Table 7. The top 18 most frequently used keywords in RSAGPM research from 2000 to 2019.

\begin{tabular}{|c|c|c|c|c|c|c|c|c|c|c|c|c|}
\hline \multirow{2}{*}{ Keywords } & \multicolumn{2}{|c|}{ 2000-2019 } & \multicolumn{2}{|c|}{ 2000-2003 } & \multicolumn{2}{|c|}{ 2004-2007 } & \multicolumn{2}{|c|}{ 2008-2011 } & \multicolumn{2}{|c|}{ 2012-2015 } & \multicolumn{2}{|c|}{ 2016-2019 } \\
\hline & A & $\%$ & $\mathbf{R}(\mathrm{A})$ & $\%$ & $\mathrm{R}(\mathrm{A})$ & $\%$ & $\mathrm{R}(\mathrm{A})$ & $\%$ & $\mathrm{R}(\mathrm{A})$ & $\%$ & $\mathrm{R}(\mathrm{A})$ & $\%$ \\
\hline Remote Sensing & 56 & $52.83 \%$ & $1(4)$ & $80 \%$ & $1(6)$ & $75 \%$ & $2(5)$ & $38 \%$ & $2(7)$ & $32 \%$ & $1(34)$ & $59 \%$ \\
\hline Greenhouse/Greenhouses & 52 & $49.06 \%$ & $23(1)$ & $20 \%$ & $7(3)$ & $25 \%$ & $1(8)$ & $54 \%$ & $1(11)$ & $41 \%$ & $2(29)$ & $47 \%$ \\
\hline Satellite Imagery & 28 & $26.42 \%$ & 0 & $0 \%$ & $101(1)$ & $13 \%$ & $27(2)$ & $15 \%$ & $5(6)$ & $27 \%$ & $3(19)$ & $33 \%$ \\
\hline Agriculture & 26 & $24.53 \%$ & $2(2)$ & $40 \%$ & $4(3)$ & $38 \%$ & 0 & $0 \%$ & $6(5)$ & $23 \%$ & $4(16)$ & $28 \%$ \\
\hline Image Analysis & 19 & $17.92 \%$ & $25(1)$ & $20 \%$ & $3(4)$ & $50 \%$ & $6(3)$ & $23 \%$ & $32(2)$ & $9 \%$ & $11(9)$ & $16 \%$ \\
\hline Mapping & 19 & $17.92 \%$ & $33(1)$ & $20 \%$ & $14(2)$ & $25 \%$ & 0 & $0 \%$ & 0 & $0 \%$ & $5(15)$ & $26 \%$ \\
\hline Landsat & 19 & $17.92 \%$ & 0 & $0 \%$ & 0 & $0 \%$ & $129(1)$ & $8 \%$ & $9(4)$ & $9 \%$ & $7(14)$ & $12 \%$ \\
\hline Decision Trees & 17 & $16.04 \%$ & 0 & $0 \%$ & 0 & $0 \%$ & 0 & $0 \%$ & $13(3)$ & $14 \%$ & $6(14)$ & $24 \%$ \\
\hline Image Classification & 16 & $15.09 \%$ & $4(2)$ & $40 \%$ & $58(1)$ & $13 \%$ & $7(3)$ & $23 \%$ & $7(4)$ & $18 \%$ & $23(6)$ & $10 \%$ \\
\hline Crops & 14 & $13.21 \%$ & 0 & $0 \%$ & $10(2)$ & $25 \%$ & $69(1)$ & $8 \%$ & $26(2)$ & $9 \%$ & $10(9)$ & $16 \%$ \\
\hline Land Use & 14 & $13.21 \%$ & $32(1)$ & $20 \%$ & $67(1)$ & $13 \%$ & $8(3)$ & $23 \%$ & $36(2)$ & $9 \%$ & $16(7)$ & $12 \%$ \\
\hline Classification (of Information) & 13 & $12.26 \%$ & $11(1)$ & $20 \%$ & $32(1)$ & $13 \%$ & 0 & $0 \%$ & $10(3)$ & $14 \%$ & $13(8)$ & $14 \%$ \\
\hline Support Vector Machines & 13 & $12.26 \%$ & 0 & $0 \%$ & 0 & $0 \%$ & 0 & $0 \%$ & $20(3)$ & $14 \%$ & $9(10)$ & $17 \%$ \\
\hline Image Segmentation & 11 & $10.38 \%$ & $27(1)$ & $20 \%$ & 0 & $0 \%$ & $115(1)$ & $8 \%$ & 0 & $0 \%$ & $12(9)$ & $16 \%$ \\
\hline Worldview-2 & 11 & $10.38 \%$ & 0 & $0 \%$ & 0 & $0 \%$ & 0 & $0 \%$ & $8(4)$ & $18 \%$ & $19(7)$ & $12 \%$ \\
\hline Land Cover & 10 & $9.43 \%$ & 0 & $0 \%$ & 0 & $0 \%$ & 0 & $0 \%$ & $17(3)$ & $14 \%$ & $15(7)$ & $12 \%$ \\
\hline Photomapping & 10 & $9.43 \%$ & 0 & $0 \%$ & 0 & $0 \%$ & 0 & $0 \%$ & 0 & $0 \%$ & $8(10)$ & $12 \%$ \\
\hline Satellites & 10 & $9.43 \%$ & $5(2)$ & $40 \%$ & $102(1)$ & $13 \%$ & $181(1)$ & $8 \%$ & $45(2)$ & $9 \%$ & $40(4)$ & $7 \%$ \\
\hline
\end{tabular}

A: total number of publications containing the keyword; R: ranking position.

"Remote Sensing" and "Agriculture" were the most repeated keywords from the list in the 2000-2003 sub-period. In this first period, research was mainly oriented towards the territorial development of plastic-covered crops. During the second period (2004-2007), research preferences for keywords changed slightly. Although "Remote Sensing" continued to occupy the first position in the ranking, keywords that refer to "Image Analysis" and "Crops" emerged, displacing the keyword 
"Greenhouse" from the first position. The periods 2008-2011 and 2012-2015 represented a shift towards the current configuration of the keyword research framework. In fact, the "Satellite Imagery" keyword, along with related terms like "Landsat" and "Image Classification", managed to climb to fifth place in the ranking. Furthermore, the term "Greenhouse" clearly confirmed its main role for the RSAGPM topic. The last period, 2016-2019, maintained the marked trend established during the two previous sub-periods. In this way, the final classification was configured in a similar way to that offered by the set of the last sub-periods due to an increasing number of publications and, consequently, to the increase in the number of keywords used.

Figure 6 shows the network map that links the keywords to the entire sample of the publications analyzed. The size of the circle represents the number of publications in which each keyword appears, and the color represents the cluster in which the keyword is included according to the number of co-appearances. The first cluster (light brown) falls under the term "Remote Sensing". It is also the cluster with the highest number of connections. The second group (blue) has "Greenhouse" as its main keyword, representing the productive agrosystem in which the analyzed topic focuses (intensive crop production). In the third group (red), the most frequent terms are "Satellite Imagery", "Image Analysis", "Mapping", and "Image Classification", which represent the most frequent tools (image analysis/classification from satellite imagery for mapping greenhouses) used to carry out the extraction and analysis of significant information from remote sensing data on the topic studied. The other colored clusters mainly refer to different methodologies for analyzing image data (e.g., "Object-based image analysis"); thus, they have less representation in Figure 6.

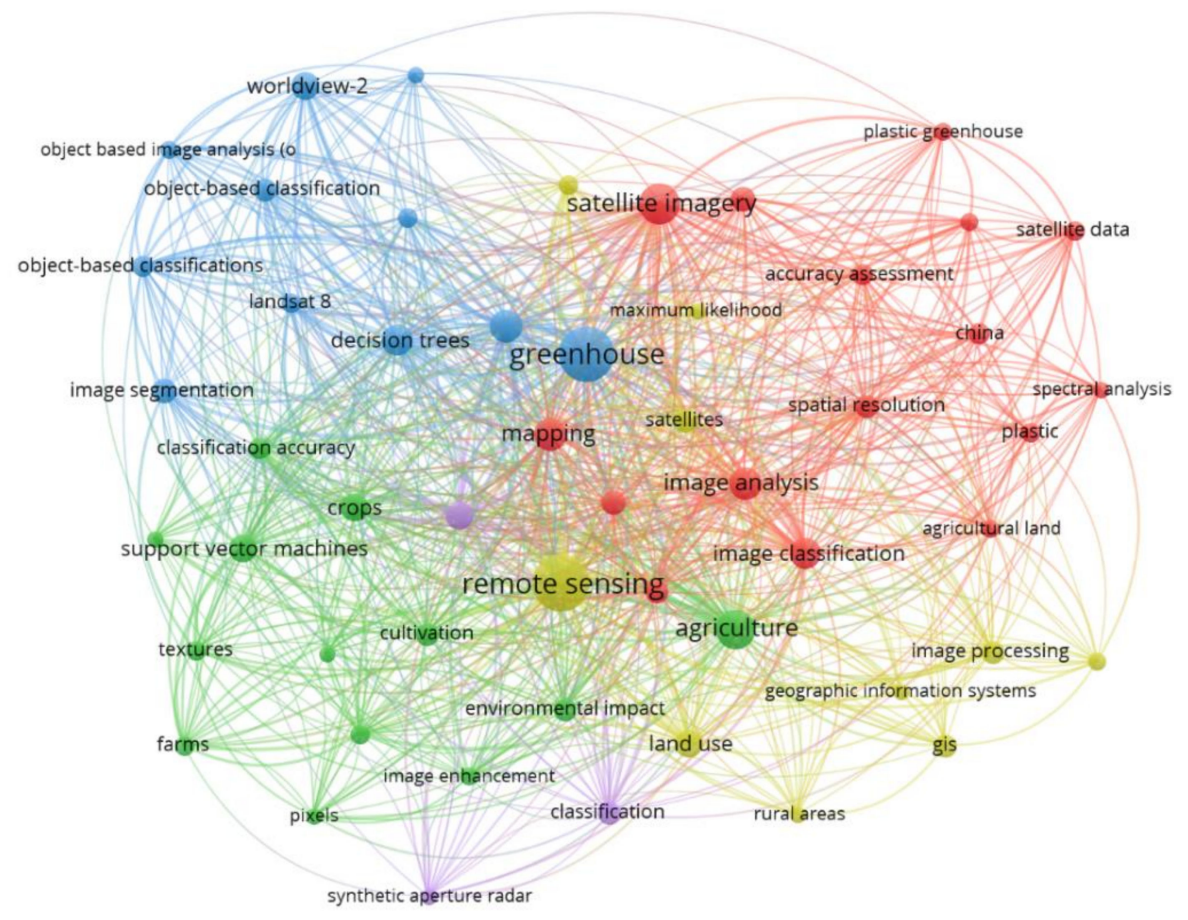

Figure 6. Keywords network in RSAGPM research from 2000 to 2019.

\section{Discussion}

The aim of this study was to carry out a rigorous bibliometric analysis to provide quantitative data about the status of international research on RSAGPM throughout the 21st century based on objective indicators such as (i) evolution of scientific production, (ii) main actors involved (research groups, institutions, and countries), (iii) information dissemination and search tools (Scopus-indexed journals/conferences and keywords), (iv) scientific impact (citations, h-index), and (v) scientific collaboration networks. Note that bibliometric methods are now firmly established as scientific 
specialties and are an integral part of the research evaluation methodology, especially within the scientific and applied fields [56]. In this way, this approach should not be confused with a review article, as the latter tries to summarize critically selected scientific content by using an extensive bibliography of the field. In contrast, a bibliometric analysis focuses on statistical related data, being driven by a need to evaluate scientific production and make the results available to researchers, policymakers, or other stakeholders [56].

Regarding the limitations of the current study, the subject analyzed has proven to be an incipient research discipline within remote sensing. In fact, scientific production has only increased remarkably during the last five years, and the number of indexed Scopus documents registered during the 21st century can be considered very low (107 documents including conference papers). It is worth noting that citations not only take time to accumulate but also continue to accumulate over time [57]. Some studies have shown that documents need at least two to three years after publication to accumulate enough citations for bibliometric indicators to be reliable [58,59]. In this sense, the pioneering countries on the topic of RSAGPM, such as Spain and Italy, with more than 450 citations each and only a few institutions involved (only the University of Almería in Spain and four institutions in Italy), formed the core of the topic for some years. Later, China was added, although it broke in strongly, having currently accumulated almost 450 citations and up to eight institutions among the 16 most productive institutions in the world.

What are the reasons behind the rise in scientific publications on RSAGPM in recent years? Without a doubt, plastic-covered agriculture has represented a great shift in the evolution from traditional agriculture to industrial agriculture. At the same time, there has been a growing awareness throughout the 21st century about its environmental impact associated with the generation of plastic waste, soil contamination, visual impact, degradation of biodiversity, and alteration of local runoff, among others. In addition, it is urgent to understand the climate-water-energy-food (CWEF) nexus and rationalize water-related policies in a scenario in which the demand for water, energy, and food will grow by approximately $40 \%, 50 \%$, and 35\%, respectively, by 2030, due to expanding world population and consumption patterns [60]. Specific CWEF nexus policies are urgently needed for the sustainable management of resources and the creation of new synergies between nexus actors through water diplomacy. Such policies are important to avoid competition for natural resources and the resulting negative effects on ecosystems and their services [61]. In this context, plastic-covered agriculture (food component) will play a relevant role, and a growing demand is anticipated to develop efficient and precise mapping and monitoring tools to determine the spatio-temporal locations of production/consumption units (e.g., greenhouse structures and associated crops). Since conventional methods for the development of inventories of production units based on in situ studies (ground-monitoring) are expensive and inefficient, they are being replaced by semi-automatic methods based on machine learning technology applied to geo-referenced digital information commonly extracted from the growing industry of satellite imagery [17,19].

With respect to detected research trends on the topic, many researchers have tried to improve the accuracy of PCG and PMF mapping by applying both PB and OBIA supervised classification algorithms to high and medium resolution satellite imagery and by means of both static and multitemporal approaches, reporting overall accuracy ranging between $85 \%$ and $98 \%$. OBIA usually provides better accuracy results than $\mathrm{PB}$, while time series approaches frequently overcome those based on mono-temporal data, although the accuracy results turn out to be highly dependent on the arrangement of each study site and the characteristics (e.g., radiometry, off-nadir angle, sun position) of the data sources.

In the next few years, we foresee a trend towards research lines in RSAGPM related to combining data from different remote sensors (e.g., optical imagery, SAR, LiDAR, and hyperspectral) and even detecting and classifying under greenhouse crops. Very recently, Nemmaoui et al. [62] carried out a pioneering work based on an OBIA approach, DT classifier, and time series of Landsat-8 and Sentinel-2 images, which dealt not only with mapping PCG but also identifying under greenhouse horticultural 
crops in Southern Spain. The segmentation stage was carried out by applying a multi-resolution segmentation algorithm [63] on preprocessed WV2 data. They attained an overall accuracy figure of 93.97\% in extracting PCG. With regard to the classification of crops under PCG, pepper in autumn and melon and watermelon in spring provided the best results $\left(\mathrm{F}_{\beta}\right.$ around $84 \%$ and $95 \%$, respectively). In this case, it was crucial to count on time series satellite images throughout the different growing seasons to increase the stability and robustness of the DT model developed, which is currently favored by the combination of data from Sentinel-2 (2A/2B) and Landsat- 8 that provide a global average revisit interval of 2.9 days [64] and reasonable consistency regarding the similarity between their multiband surface reflectance over PCG land cover [65].

With few exceptions focused on PMF land cover extraction [31,42,66], SAR data has been practically not used as a data source for PCG mapping. However, with the very recent arrival of very high spatio-temporal resolution SAR data provided by the new generation of small satellites (e.g., ICEYE SAR (https://www.iceye.com/)), with X-band radar imaging available even at a $1 \mathrm{~m}$ ground sample distance resolution [67], it is likely that there will be a need to test its promising potential in RSAGPM. Further work is needed in order to understand the physical aspects of the interaction between microwaves and plastic film sheets.

Deep learning technology has recently demonstrated that it can be applied to crop-type mapping, obtaining even better performance than object-oriented machine learning methods when dealing with remote sensing image classification problems [68,69]. However, to the best of our knowledge, only one report has been published in which a deep learning Single Shot MultiBox Detector (SSD) was applied to detect agricultural greenhouses using images from GaoFen series satellites [70]. Therefore, much remains to be done in this field, especially with regards to greenhouse crop detection from high resolution time series imagery taken throughout the growing season.

In the same way, the rise of the new breed of very high resolution optical satellites allows us to obtain stereo images for the extraction of digital surface models (DSM) with reasonable altimetric accuracy using automatic correlation photogrammetric procedures [71]. Although few works have specifically focused on PCG areas [40,72,73], Aguilar et al. [40] and Celik and Koc-San [74] proved the importance of integrating the normalized digital surface model (nDSM) for improving PCG mapping accuracy.

Finally, from our point of view, it would be necessary to go a step further by delving into the physical phenomenon of the transmittance of electromagnetic radiation through the plastic cover and of the reflectance that actually reaches the remote sensor after passing through the plastic film, depending on real field conditions such as plastic film type and thickness, age of and dirt on the plastic sheet, roof geometry, presence of double plastic cover, crop management, and crop development and phenology.

\section{Conclusions}

The results obtained in this work showed that the selected scientific communications were mostly published in articles $(66 \%)$ and conference papers $(32 \%)$, being predominantly published in English $(95 \%)$. The results of the bibliometric analysis indicated that the number of articles per year increased exponentially, growing from one document published in 2001 to 22 in 2019 . There was a particularly strong increase in the last four years, in which more than $55 \%$ of all documents were published.

The main categories with respect to the analyzed topic were Earth and Planetary Sciences (53\%), Computer Science (30\%), and Agricultural and Biological Sciences (28\%). The results obtained point to an increasing number of journals that publish research on RSAGPM, highlighting the "Remote Sensing" journal, with 22 articles published since its appearance in 2009.

The country with the highest number of documents published was China, while the University of Almeria (Spain) was the top institution in RSAGPM research, showing close collaboration with some Italian universities. In fact, China and Spain/Italy were the two main clusters worldwide producing research on RSAGPM, which is strongly correlated with the extent and economic importance of this kind of intensive agrosystem in China and the Mediterranean countries. 
In summary, the evolution of the number of publications on RSAGPM found throughout the period 2000-2019 allows the classification of the subject studied as an emerging research topic that is attracting an increasing level of interest worldwide, although its relative significance is still very limited within the remote sensing discipline. Nevertheless, the growing demand for information on the arrangement and spatio-temporal dynamics of this increasingly important model of intensive agriculture will likely boost this research line in the next few years.

Author Contributions: R.J.-L. collected the input data and performed the experiments, additionally collaborating in manuscript writing and revision. F.J.A. proposed the methodology and designed and conducted the experiments. He also contributed extensively to manuscript writing and revision. M.A.A. made significant contributions to the research design and manuscript preparation, providing suggestions for the methodology design and manuscript revision. A.N. made significant contributions to the collection and analysis of the data. All authors have read and agreed to the published version of the manuscript.

Funding: This research was funded by the Spanish Ministry for Science, Innovation and Universities (Spain) and the European Union (European Regional Development Fund, ERDF) funds (Grant Reference RTI2018-095403-B-I00).

Acknowledgments: We acknowledge the support of the Spanish Ministry for Science, Innovation and Universities (Spain) and the European Union (European Regional Development Fund, ERDF) funds (Grant Reference RTI2018-095403-B-I00). This study takes part in the general research lines promoted by the Agrifood Campus of International Excellence ceiA3 (http://www.ceia3.es/).

Conflicts of Interest: The authors declare no conflict of interest.

\section{References}

1. Espí, E.; Salmerón, A.; Fontecha, A.; García, Y.; Real, A.I. Plastic films for agricultural applications. J. Plast. Film Sheeting 2006, 22, 85-102. [CrossRef]

2. González-Yebra, Ó.; Aguilar, M.A.; Nemmaoui, A.; Aguilar, F.J. Methodological proposal to assess plastic greenhouses land cover change from the combination of archival aerial orthoimages and Landsat data. Biosyst. Eng. 2018, 175, 36-51. [CrossRef]

3. Wu, C.; Deng, J.; Wang, K.; Ma, L.; Tahmassebi, A.R.S. Object-based classification approach for greenhouse mapping using Landsat-8 imagery. Int. J. Agric. Biol. Eng. 2016, 9, 79-88.

4. Yan, C.; He, W.; Liu, E.; Lin, T.; Pasquale, M.; Liu, S.; Liu, Q. Concept and estimation of crop safety period of plastic film mulching. Transations Chin. Soc. Agric. Eng. 2015, 31, 1-4. [CrossRef]

5. Yan, C.; Liu, E.; Shu Mei, F.; Liu, Q.; Liu, S.; He, W. Review of agricultural plastic mulching and its residual pollution and prevention measures in China. J. Agric. Resour. Environ. 2014, 31, 95-102.

6. Hasituya; Chen, Z. Mapping Plastic-Mulched Farmland with Multi-Temporal Landsat-8 Data. Remote Sens. 2017, 9, 557. [CrossRef]

7. Garnaud, J.C. Plasticulture: Bulletin du comité international des plastiques en agriculture. Plasticulture 2000, $119,30-43$.

8. Takakura, T.; Fang, W. Climate under Cover, 2nd ed.; Springer: Dordrecht, The Netherlands, 2002; ISBN 978-1-4020-0845-0.

9. Jiang, W.J.; Yu, H.J. Present Situation and Future Development for Protected Horticulture in Mainland China. In Proceedings of the Acta Horticulturae; International Society for Horticultural Science: Leuven, Belgium, 2008; Volume 770, pp. 29-35.

10. Molina-Aiz, F.D.; Valera, D.L.; Álvarez, A.J. Measurement and simulation of climate inside Almería-type greenhouses using computational fluid dynamics. Agric. For. Meteorol. 2004, 125, 33-51. [CrossRef]

11. Lu, L.; Di, L.; Ye, Y. A decision-tree classifier for extracting transparent plastic-mulched Landcover from landsat-5 TM images. IEEE J. Sel. Top. Appl. Earth Obs. Remote Sens. 2014, 7, 4548-4558. [CrossRef]

12. Parra, S.; Aguilar, F.J.; Calatrava, J. Decision modelling for environmental protection: The contingent valuation method applied to greenhouse waste management. Biosyst. Eng. 2008, 99, 469-477. [CrossRef]

13. Thompson, R.B.; Padilla, F.M.; Peña-Fleitas, M.T.; Gallardo, M. Reducing nitrate leaching losses from vegetable production in Mediterranean greenhouses. Acta Hortic. 2020, 1268, 105-117. [CrossRef]

14. Arcidiacono, C.; Porto, S.M.C. A model to manage crop-shelter spatial development by multi-temporal coverage analysis and spatial indicators. Biosyst. Eng. 2010, 107, 107-122. [CrossRef] 
15. Rogge, E.; Nevens, F.; Gulinck, H. Reducing the visual impact of "greenhouse parks" in rural landscapes. Landsc. Urban Plan. 2008, 87, 76-83. [CrossRef]

16. Quintas-Soriano, C.; Castro, A.J.; Castro, H.; García-Llorente, M. Impacts of land use change on ecosystem services and implications for human well-being in Spanish drylands. Land Use Policy 2016, 54, 534-548. [CrossRef]

17. Li, J.; Pei, Y.; Zhao, S.; Xiao, R.; Sang, X.; Zhang, C. A Review of Remote Sensing for Environmental Monitoring in China. Remote Sens. 2020, 12, 1130. [CrossRef]

18. Aguilar, M.A.; Vallario, A.; Aguilar, F.J.; Lorca, A.G.; Parente, C. Object-based greenhouse horticultural crop identification from multi-temporal satellite imagery: A case study in Almeria, Spain. Remote Sens. 2015, 7, 7378-7401. [CrossRef]

19. Atzberger, C. Advances in Remote Sensing of Agriculture: Context Description, Existing Operational Monitoring Systems and Major Information Needs. Remote Sens. 2013, 5, 949-981. [CrossRef]

20. Novelli, A.; Aguilar, M.A.; Nemmaoui, A.; Aguilar, F.J.; Tarantino, E. Performance evaluation of object based greenhouse detection from Sentinel-2 MSI and Landsat 8 OLI data: A case study from Almería (Spain). Int. J. Appl. Earth Obs. Geoinf. 2016, 52, 403-411. [CrossRef]

21. Levin, N.; Lugassi, R.; Ramon, U.; Braun, O.; Ben-Dor, E. Remote sensing as a tool for monitoring plasticulture in agricultural landscapes. Int. J. Remote Sens. 2007, 28, 183-202. [CrossRef]

22. Agüera, F.; Aguilar, M.A.; Aguilar, F.J. Detecting greenhouse changes from QuickBird imagery on the Mediterranean coast. Int. J. Remote Sens. 2006, 27, 4751-4767. [CrossRef]

23. Agüera, F.; Aguilar, F.J.; Aguilar, M.A. Using texture analysis to improve per-pixel classification of very high resolution images for mapping plastic greenhouses. ISPRS J. Photogramm. Remote Sens. 2008, 63, 635-646. [CrossRef]

24. Carvajal, F.; Agüera, F.; Aguilar, F.J.; Aguilar, M.A. Relationship between atmospheric corrections and training-site strategy with respect to accuracy of greenhouse detection process from very high resolution imagery. Int. J. Remote Sens. 2010, 31, 2977-2994. [CrossRef]

25. Picuno, P.; Tortora, A.; Capobianco, R.L. Analysis of plasticulture landscapes in Southern Italy through remote sensing and solid modelling techniques. Landsc. Urban Plan. 2011, 100, 45-56. [CrossRef]

26. Koc-San, D. Evaluation of different classification techniques for the detection of glass and plastic greenhouses from WorldView-2 satellite imagery. J. Appl. Remote Sens. 2013, 7, 073553. [CrossRef]

27. Pala, E.; Tasdemir, K.; Koc-San, D. Unsupervised Extraction of Greenhouses Using Approximate Spectral Clustering Ensemble. In Proceedings of the International Geoscience and Remote Sensing Symposium (IGARSS), Milan, Italy, 26-31 July 2015; Volume 2015-Novem, pp. 4668-4671.

28. Lu, L.; Hang, D.; Di, L. Threshold model for detecting transparent plastic-mulched landcover using MODIS time series data: A case study in southern Xinjiang, China. J. Appl. Remote Sens. 2015, 9, 097094. [CrossRef]

29. Hasituya; Chen, Z.X.; Wu, W.B.; Qing, H. Monitoring plastic-mulched farmland using Landsat-8 OLI imagery. In Proceedings of the 2015 4th International Conference on Agro-Geoinformatics, Agro-Geoinformatics, Istanbul, Turkey, 20-24 July 2015; pp. 292-301.

30. Hasituya; Chen, Z.; Wang, L.; Wu, W.; Jiang, Z.; Li, H. Monitoring Plastic-Mulched Farmland by Landsat-8 OLI Imagery Using Spectral and Textural Features. Remote Sens. 2016, 8, 353. [CrossRef]

31. Hasituya; Chen, Z.; Li, F. Hongmei Mapping Plastic-Mulched Farmland with C-Band Full Polarization SAR Remote Sensing Data. Remote Sens. 2017, 9, 1264. [CrossRef]

32. Novelli, A.; Tarantino, E. Combining ad hoc spectral indices based on LANDSAT-8 OLI/TIRS sensor data for the detection of plastic cover vineyard. Remote Sens. Lett. 2015, 6, 933-941. [CrossRef]

33. Yang, D.; Chen, J.; Zhou, Y.; Chen, X.; Chen, X.; Cao, X. Mapping plastic greenhouse with medium spatial resolution satellite data: Development of a new spectral index. ISPRS J. Photogramm. Remote Sens. 2017, 128, 47-60. [CrossRef]

34. Blaschke, T. Object based image analysis for remote sensing. ISPRS J. Photogramm. Remote Sens. 2010, 65, 2-16. [CrossRef]

35. Tarantino, E.; Figorito, B. Mapping Rural Areas with Widespread Plastic Covered Vineyards Using True Color Aerial Data. Remote Sens. 2012, 4, 1913-1928. [CrossRef]

36. Balcik, F.B.; Senel, G.; Goksel, C. Greenhouse mapping using object based classification and sentinel-2 satellite imagery. In Proceedings of the 2019 8th International Conference on Agro-Geoinformatics, Agro-Geoinformatics, Istanbul, Turkey, 16-19 July 2019; pp. 1-5. 
37. Arcidiacono, C.; Porto, S.M.C. Improving per-pixel classification of crop-shelter coverage by texture analyses of high-resolution satellite panchromatic images. J. Agric. Eng. 2012, 42, 9-16. [CrossRef]

38. Lanorte, A.; De Santis, F.; Nolè, G.; Blanco, I.; Loisi, R.V.; Schettini, E.; Vox, G. Agricultural plastic waste spatial estimation by Landsat 8 satellite images. Comput. Electron. Agric. 2017, 141, 35-45. [CrossRef]

39. Arcidiacono, C.; M.C.Porto, S. Classification of crop-shelter coverage by RGB aerial images: A compendium of experiences and findings. J. Agric. Eng. 2010, 41, 1-11. [CrossRef]

40. Aguilar, M.A.; Bianconi, F.; Aguilar, F.J.; Fernández, I. Object-based greenhouse classification from GeoEye-1 and WorldView-2 stereo imagery. Remote Sens. 2014, 6, 3554-3582. [CrossRef]

41. Aguilar, M.A.; Nemmaoui, A.; Novelli, A.; Aguilar, F.J.; Lorca, A.G. Object-based greenhouse mapping using very high resolution satellite data and Landsat 8 time series. Remote Sens. 2016, 8, 513. [CrossRef]

42. Lu, L.; Tao, Y.; Di, L. Object-Based Plastic-Mulched Landcover Extraction Using Integrated Sentinel-1 and Sentinel-2 Data. Remote Sens. 2018, 10, 1820. [CrossRef]

43. Hood, W.W.; Wilson, C.S. The literature of bibliometrics, scientometrics, and informetrics. Scientometrics 2001, 52, 291-314. [CrossRef]

44. Gomez-Jauregui, V.; Gomez-Jauregui, C.; Manchado, C.; Otero, C. Information management and improvement of citation indices. Int. J. Inf. Manag. 2014, 34, 257-271. [CrossRef]

45. Velasco-Muñoz, J.; Aznar-Sánchez, J.; Belmonte-Ureña, L.; Román-Sánchez, I. Sustainable Water Use in Agriculture: A Review of Worldwide Research. Sustainability 2018, 10, 1084. [CrossRef]

46. Aznar-Sánchez, J.; Belmonte-Ureña, L.; López-Serrano, M.; Velasco-Muñoz, J. Forest Ecosystem Services: An Analysis of Worldwide Research. Forests 2018, 9, 453. [CrossRef]

47. Suominen, A.; Toivanen, H. Map of science with topic modeling: Comparison of unsupervised learning and human-assigned subject classification. J. Assoc. Inf. Sci. Technol. 2016, 67, 2464-2476. [CrossRef]

48. Valérie, D.; Pierre, A.G. Bibliometric idicators: Quality masurements of sientific publication. Radiology 2010, 255, 342-351.

49. Hirsch, J.E. An index to quantify an individual's scientific research output. Proc. Natl. Acad. Sci. USA 2005, 102, 16569-16572. [CrossRef] [PubMed]

50. González-Pereira, B.; Guerrero-Bote, V.P.; Moya-Anegón, F. A new approach to the metric of journals scientific prestige: The SJR indicator. J. Informetr. 2010, 4, 379-391. [CrossRef]

51. Waltman, L.; van Eck, N.J.; Noyons, E.C.M. A unified approach to mapping and clustering of bibliometric networks. J. Informetr. 2010, 4, 629-635. [CrossRef]

52. Perianes-Rodriguez, A.; Waltman, L.; van Eck, N.J. Constructing bibliometric networks: A comparison between full and fractional counting. J. Informetr. 2016, 10, 1178-1195. [CrossRef]

53. Mongeon, P.; Paul-Hus, A. The journal coverage of Web of Science and Scopus: A comparative analysis. Scientometrics 2016, 106, 213-228. [CrossRef]

54. Gavel, Y.; Iselid, L. Web of Science and Scopus: A journal title overlap study. Online Inf. Rev. 2008, 32, 8-21. [CrossRef]

55. Velasco-Muñoz, J.F.; Aznar-Sánchez, J.A.; Belmonte-Ureña, L.J.; López-Serrano, M.J. Advances in Water Use Efficiency in Agriculture: A Bibliometric Analysis. Water 2018, 10, 377. [CrossRef]

56. Ellegaard, O.; Wallin, J.A. The bibliometric analysis of scholarly production: How great is the impact? Scientometrics 2015, 105, 1809-1831. [CrossRef] [PubMed]

57. Belter, C.W. Bibliometric indicators: Opportunities and limits. J. Med. Libr. Assoc. 2015, 103, $219-221$. [CrossRef] [PubMed]

58. Abramo, G.; Cicero, T.; D'Angelo, C.A. Assessing the varying level of impact measurement accuracy as a function of the citation window length. J. Informetr. 2011, 5, 659-667. [CrossRef]

59. Wang, J. Citation time window choice for research impact evaluation. Scientometrics 2013, 94, 851-872. [CrossRef]

60. European Commision. Building a low-carbon, climate resilient future: Climate action in support of the Paris Agreement. Call H2020-LC-CLA-2018-2019-2020. Available online: https://ec.europa.eu/info/fundingtenders/opportunities/portal/screen/opportunities/topic-details/lc-cla-14-2020 (accessed on 7 August 2020).

61. UNECE Water Convention. Available online: https://www.unece.org/env/water/text/text.html (accessed on 7 August 2020). 
62. Nemmaoui, A.; Aguilar, M.A.; Aguilar, F.J.; Novelli, A.; García Lorca, A. Greenhouse Crop Identification from Multi-Temporal Multi-Sensor Satellite Imagery Using Object-Based Approach: A Case Study from Almería (Spain). Remote Sens. 2018, 10, 1751. [CrossRef]

63. Baatz, M.; Schäpe, A. Multiresolution Segmentation: An optimization approach for high quality multi-scale image segmentation. In Angewandte Geographische Informationsverarbeitung XII; Beiträge zum AGIT. Salzburg 2000; Karlsruhe; Strobl, J., Ed.; Herbert Wichmann Verlag: Heidelberg, Germany, 2000; pp. 12-23.

64. Li, J.; Roy, D.P. A Global Analysis of Sentinel-2A, Sentinel-2B and Landsat-8 Data Revisit Intervals and Implications for Terrestrial Monitoring. Remote Sens. 2017, 9, 902.

65. Aguilar, M.Á.; Jiménez-Lao, R.; Nemmaoui, A.; Aguilar, F.J.; Koc-San, D.; Tarantino, E.; Chourak, M. Evaluation of the Consistency of Simultaneously Acquired Sentinel-2 and Landsat 8 Imagery on Plastic Covered Greenhouses. Remote Sens. 2020, 12, 2015. [CrossRef]

66. Liu, C.-A.; Chen, Z.; Wang, D.; Li, D. Assessment of the X- and C-Band Polarimetric SAR Data for Plastic-Mulched Farmland Classification. Remote Sens. 2019, 11, 660. [CrossRef]

67. Saito, H.; Hirokawa, J.; Tomura, T.; Akbar, P.R.; Pyne, B.; Tanaka, K.; Mita, M.; Kaneko, T.; Watanabe, H.; Ijichi, K. Development of Compact SAR Systems for Small Satellite. In Proceedings of the International Geoscience and Remote Sensing Symposium (IGARSS), Yokohama, Japan, 28 July-2 August 2019; pp. 8440-8443.

68. Zhu, X.X.; Tuia, D.; Mou, L.; Xia, G.S.; Zhang, L.; Xu, F.; Fraundorfer, F. Deep Learning in Remote Sensing: A Comprehensive Review and List of Resources. IEEE Geosci. Remote Sens. Mag. 2017, 5, 8-36. [CrossRef]

69. Kussul, N.; Lavreniuk, M.; Skakun, S.; Shelestov, A. Deep Learning Classification of Land Cover and Crop Types Using Remote Sensing Data. IEEE Geosci. Remote Sens. Lett. 2017, 14, 778-782. [CrossRef]

70. Zhao, J. Agricultural Greenhouses Extraction Based on GF-2 Remote Sensing Images; North China Institute of Aerospace Engineering: Langfang, China, 2019.

71. Aguilar, M.A.; Saldaña, M.M.; Aguilar, F.J. Generation and Quality Assessment of Stereo-Extracted DSM From GeoEye-1 and WorldView-2 Imagery. IEEE Trans. Geosci. Remote Sens. 2014, 52, 1259-1271. [CrossRef]

72. Aguilar, M.A.; Nemmaoui, A.; Aguilar, F.J.; Qin, R. Quality assessment of digital surface models extracted from WorldView-2 and WorldView-3 stereo pairs over different land covers. GIScience Remote Sens. 2018, 56, 109-129. [CrossRef]

73. Nemmaoui, A.; Aguilar, F.J.; Aguilar, M.A.; Qin, R. DSM and DTM generation from VHR satellite stereo imagery over plastic covered greenhouse areas. Comput. Electron. Agric. 2019, 164, 104903. [CrossRef]

74. Celik, S.; Koc-San, D. Greenhouse detection using aerial orthophoto and digital surface model. In Smart Innovation, Systems and Technologies; Springer Science and Business Media: Berlin/Heidelberg, Germany, 2018; Volume 76, pp. 51-59. 